\title{
CONSIDERAÇÕES SOBRE YAMABE NO AKAHITO, UM POETA DO SÉCULO VIII
}

Geny Wakisaka

Em Nihonshoki' ${ }^{1}$, anais e crônicas históricas do Japão, elaborado em 720, encontramos o sobrenome "Yamabe", no episódio em que o país está à procura dos sucessores do 220 imperador Seinei (480-485). Consta que Iyo Kumebe Kotate, antepassado de "Yamabe no muraji", chefe da província de Harima, é agraciado com o cargo de "Guarda Florestal" pelos serviços prestados à Corte no referido episódio, localizando os príncipes Okeno miko e Wokeno miko, respectivamente os $23{ }^{\circ}$ e $249^{\circ}$ imperadores do país. Nihonshoki ${ }^{2}$ assinala novamente este sobrenome quando o seu portador é condecorādo com o título de Sukune (3! grau na escala de funcionalismo público de então), no ano 12 do imperador Tenmu que corresponde ao ano 684. 0 sobrenome em questão desaparece dos anais do país. Os estudiosos do poeta Yamabe no skune Akahito, que não nos legou seus dados biográficos, consideram seus antepassados os acima citadọs.

A primeira antologia poética japonesa Manyooshuu, elaborada no século VIII, registra cinquenta obras poéticas de Yamabe no sukune Akahito (abrev. Akahito d.p.f.), assim nela distribuídas:

\begin{tabular}{|c|c|c|c|}
\hline vol. & no de poemas & tipo de & oemas \\
\hline \multirow[b]{2}{*}{3} & & chooka & tanka \\
\hline & 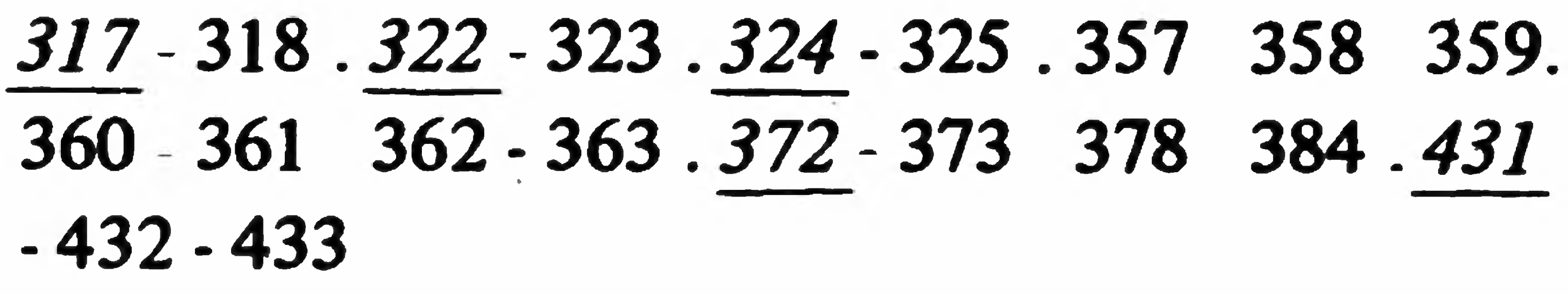 & \multirow[t]{2}{*}{5} & \multirow[t]{2}{*}{15} \\
\hline 6 & 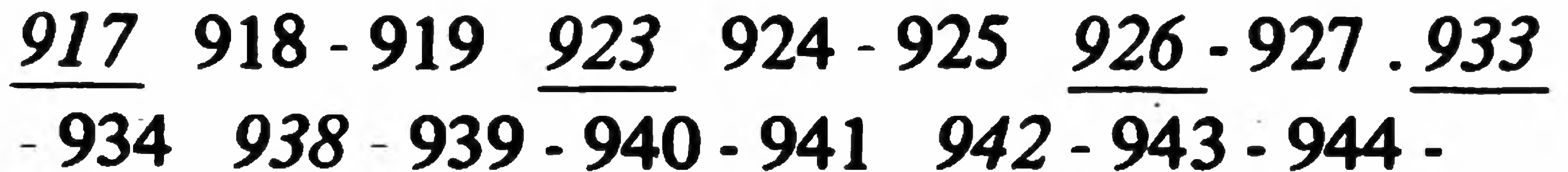 & & \\
\hline & $\begin{array}{llllll}-945 & 946 & 947 & 1001 & 1005 & 1006\end{array}$ & 8 & 15 \\
\hline 8 & $1414-1425 \quad 1426-1427 . .1431 \quad 1471$ & & 6 \\
\hline 17 & 3915 & & 1 \\
\hline
\end{tabular}


Os números sublinhados no quadro acima săo dos poemas classificados quanto à sua forma em tipo "chooka" (poema longo de 5-7-5-7-.....5-7-7. sílabas) e os não sublinhados, os ditos "tanka" (poema curto de 31 sílabas). Os que estão unidos por um traço (-) envolvem o mesmo tema e neste caso os "tanka" que sucedem o "chooka" do grupo, recebem a denominação especial de "hanka" funcionando como sintetizador, reforço ou complemento da temática desenvolvida no "chooka" que os precede.

Para situarmos o poeta Akahito no tempo, podemos nos basear nas anotaçбes que estáo antepostas (Daishi) ou pospostas (Sa chuu) aos seus poemas ou, às vezes, àquelas dos poemas que precedem aos do poeta na seqüência numérica da antologia Manyooshuu. Esquematizando-se estas anotaçōes obteremos o seguinte quadro:

\begin{tabular}{|c|c|c|}
\hline vol. & no & Data de elaboração \\
\hline 6 & $917-919$ & $\begin{array}{r}5 \text { de outubro do ano } 1 \text { da era Shinki (724). Viagem } \\
\text { imperial à Kyi. }\end{array}$ \\
\hline 6 & 923-927 & $\begin{array}{l}\text { maio verão do ano } 2 \text { da era Shinki (725). Viagem } \\
\text { imperial à Yoshino. (nota do n? } 920 \text { ). }\end{array}$ \\
\hline 6 & $933-934$ & $\begin{array}{l}\text { outubro do ano } 2 \text { da era Shinki ( } 725) \text {. Viagem im- } \\
\text { perial a Naniwa. (nota do no } 928 \text { ). }\end{array}$ \\
\hline 6 & $938-941$ & $\begin{array}{l}15 \text { de setembro outono do ano } 3 \text { da era Shinki (726). } \\
\text { Viagem imperial à Harima. (nota do no 935). }\end{array}$ \\
\hline 6 & 1001 & $\begin{array}{l}\text { março do ano } 6 \text { da era Tempyoo (734). Viagem impe- } \\
\text { rial à Naniwa. (nota do no 997). }\end{array}$ \\
\hline 6 & $1005-1006$ & $\begin{array}{l}\text { junho verão do ano } 8 \text { da era Tempyoo (736). Via- } \\
\text { gem imperial à Yoshino. }\end{array}$ \\
\hline
\end{tabular}

Verificamos pelo quadro acima que todas as obras poéticas de Akahito, de datas de elaboração esclarecidas, estáo inseridas no volume 6 da antologia Manyooshuu. Este volume reune poemas elaborados por volta dos anos 720 a 750, dispostos em ordem cronológica, destacando-se nele as temáticas desenvolvidas sobre as viagens imperiais.

Pelos dados acima coletados, temos o conhecimento de que do ano 724 ao 736 , históricamente conhecido no Japáo como o período Nara, segundo dados oficiais, o país está sob o seu 459 imperador Shoomu (724-738) e nota-se que Akahito acompanha a comitiva imperial em suas viagens recreativas pelo país, juntamente com Kassa no Kanamura e Kurumamochi no Chitosse, autores das obras poéticas de cujas anotações nos servimos|para a elaboração do quadro acima, todos na qualidade de poeta da Corte.

$O$ poeta da Corte tinha normalmente um posto de baixa categoria dentro do sistema de governo e quando solicitado pela Corte, elaborava os poemas para a ocasião, onde sempre as palavras de sublimação ao imperador ou 
de exaltação ao país estavam presentes. Vez por outra ele atuava como "Ghost writer"

Poemas eram requisitados frequentemente nas solenidades múltiplas realizadas pela Corte como a caça, a colheita de ervas organizadas em campos privativos, viagens imperiais e mortes de dignitários. Mesmo na pré-história, verifica-se que esta função cabia a certas mulheres idôneas, cujos poemas-canções primavam pelo seu caráter místico. Na era Hakuhoo (645-710), durante a implantação do Sistema Ritsuryoo, cópia do modelo jurídico-administrativo chinês, no Japão, visando a consolidação da autoridade plena e absoluta da famnlia imperial e quando ele se fez definitivo, o poeta da Corte é naturalmente o porta voz do grupo dominante, sendo aos poucos as mulheres substituídas pelos homens no cargo, exigindo-se-lhes conhecimento da cultura chinesa. Destaca-se nesta era o grandiloqüente Kakino motono Hitomaro ${ }^{3}$, cognominado "o poeta divino da antiguidade" Já no período Nara (710-793), subsequente, o Sistema Ritsuryoo implantado com tanto entusiasmo até então e que graduava o homem numa escala de trabalhos e títulos sujeitando-o ao controle de um único déspota, sofre o seu desgaste, apresentando rupturas, permitindo a atuaçáo cada vez mais progressiva da nobreza no quadro político da nação. A voz do poeta da Corte perde a sua vitalidade por falta também de uma ressonância mais clara em sua platéia ainda restrita, mas de interesses matizados. E é desta época o poeta Akahito.

Os poemas da antologia Manyooshuu, grosso modo, são classificados quanto às suas temáticas em Banka, Soomon e Zooka.

Banka é o poema elegíaco cuja temática gira em tomo da morte de alguém. Esta designação é originária da China e adaptada no Japão a este tipo de poemas já existentes no país, influenciado sobremodo pelos poemas da coletânea Monzen elaborada naquele país por volta do século Vl. Seu nome Banka significa canção de transporte do esquife, costume verificado na China. O tipo Soomon expõe o relacionamento humano inspirado talvez nas epístolas amorosas chinesas. Tecem linhas do bem querer, surgindo como diálogos poéticos que mais tarde se desenvolvem para a expressão do ego. Zooka cuja temática escapa às classificações anteriores, engloba os temas de viagens e solenidades oficiais.

Nota-se com relativa freqüência na antologia Manyooshuu a presença de poemas tipo Banka, solenemente compostos pelos poetas da Corte. No âmbito são destacados os poemas, vol. 3/426. 429-430. vol. 2/196-198. 199. -201., pomposamente elaborados por Kakino motono Hitomaro. Akahito porém, não registrou nenhum poema tipo Banka.

Em 728, após completar um ano de existência, o primogênito do imperador Shoomu, concebido pela cortesã Assuka, filha da família Fujiwara, teve morte súbita. Um ano -mais tarde, o príncipe Nagaya, braço direito do imperador, politicamente contrário à participação da nobreza nos assuntos seculares e evidentemente inimigo político dos Fujiwara, é tragicamente compelido à morte, incriminado, sem provas convincentes, pela morte do príncipe 
herdeiro. São duas mortes que abalaram o quadro político da época e, no entanto, não se registrou um Banka sequer do poeta em questāo. Esta sua omissão poderá ter múltiplas justificativas, mas não deixa de causar estranheza. o seguinte:

A anotação anteposta ao poema 378 da referida antologia poética diz no Fuhito"

"Poema de Akahito, que canta os jardins do falecido ministro Fujiwara

Adiantando-se as anotaçðes, o referido ministro falece em Agosto do ano 4 da era Yooroo (720). Diz o poema:

vol. $3 / 378$

"Inishieno furuki tsutsumiwa toshifukami ikeno naguissani mikussa oinikeri"

- Nos antigos gastos barrancos anos se afundam nas margens do lago medram plantas aquáticas

Considerado o poeta da Corte do imperador Shoomu, desde que este tomara posse, presume-se que Akahito vinha servindo a ele já desde a sua mocidade. Como ditavam os costumes da Corte, o príncipe fora educado na sua infância em casa de seu avô materno Fujiwara no Fuhito, donde o acesso de Akahito aos jardins deste ilustre nobre. Segundo o prof. Kawaguchi Tsuneta$\mathbf{k a}^{4}$, que pesquisa inclusive a biografia do poeta em questão, este teria convivido com a familia Fujiwara, dos seus 21 aos 27 anos servindo-a na qualidade de Toneri (encarregado da guarda ou serviços generalizados aos fidalgos categorizados ou à familia imperial) e o tanka 378 acima transcrito, data provavelmente por volta de 723, no mínimo trés anos após a morte do ministro. Convenhamos que até a referida data, Akahito não atuava como poeta da Corte, porém, a morte de um dignitário tão chegado a ele não o teria sensibilizado? 0 referido tanka nos apresenta a transfiguração dos jardins carentes de cuidados, numa sutil descrição. 'A desolação provém do quadro suscitado em si num solilóquio poético pois, o passamento de Fuhito apenas vem registrado nas anotações do poema. O que se pode afirmar é que há um nítido alheamento do poeta em relação às pessoas ligadas ao poder de então. $\dot{E}$ de se estranhar, de outra parte, que o poeta não tenha presenciado a morte de alguém de seu relacionamento mais intimo durante os seus 44 ou 45 anos de vida, calculados pelo prof. Kawaguchi já citado. Ou isto comprova a sua condição de completa orfandade - o homem sem biografia e que só deixou rastros poéticos.

Na triologia 431-432-433 do volume 3 do Manyooshuu, Akahito evoca a figura lendária da jovem Tekona, beldade cuja tumba diz ele ter encontrado, quando de sua passagem por Katsushika na atual província de Chiba. No chooka 431. o poeta relata os amores da jovem e a situação presente de sua sepultura, coberta de raizes e folhas secas; no hanka 432 , a descoberta da tumba e no 433. a imagem da jovem colhendo algas é aludida com carinho. Apesar de 
tratar-se de uma jovem lendária do passado, a morte se faz tãó distante que o poema não se apresenta como do tipo Banka onde lágrimas seriam também esperadas. Não passa pois a trilogia, de uma homenagem a uma lenda em tons de monólogo do poeta. $O$ fato é que a morte em si não o inspirou, nem poeticamente nem talvez religiosamente, quando o Budismo estava em voga no país.

Muitas das obras de Akahito enquadradas no tipo Soomon foram elaboradas durante as suas viagens empreendidas a serviço da Corte. Muitas de suas anotações não especificam o caráter destas viagens, mas dificilmente um funcionário público da categoria de Akahito poderia se afastar da capital na época, em caráter particular, de onde a afirmação acima.

Os poemas 362-363 e 946 são talvez os do poeta, que poderiam ser classificados como típicos Soomon da antiguidade, em que homens e mulheres se desafiavam mutuamente para o amor. Utilizando o poeta, a técnica do "Kakekotoba", que consiste no aproveitamento das palavras de duplo sentido, ele vai desafiando as mulheres com quem cruza nas praias, talvez mulheres da vida (yuujo), convidando-as para o amor. No chooka 946, a descrição das algas "miru", termo que também tem o sentido de "ver" e que na literatura clássica aparece com o sentido de "casar-se" e, das algas "nanorisso" que significa também "identificar-se", Akahito com hábil jogo de palavras desenvolve o poema para o convite ao amor. Parecem flertes ocasionais do poeta viajante em momentos de alegre abandono. Diz ele o seguinte:

vol. $6 / 946$

"Mikemukau Awajino shimani tadamukau Minumeno urano okiheniwa fuka miru tori uraminiwa nanorisso karu fuka miru no mimakuhoshikedo nanorisso no onoga na oshimi matsukaimo yarazute warewa ikeritomo nashi".

- Ao longo da enseada de Minume, frente à ilha de Awa, colhem-se miru (algas); nas orlas da baia recolhem-se nanorisso (algas). Desejo vê-la tão intensamente (fuka miru) mas receio ser identificado (nanorisso) e sem recados, padeço sem mais viver.

No poema, além do jogo de palavras, temos a presença marcante de aliterações que o realçaria se expresso oralmente. Nota-se porém um receio incontido do poeta de que boatos o venham comprometer-lhe e neste sentido a tonalidade de monólogo, já típico do poeta, poderá ser detectado. De outra parte, a antologia Manyooshuu, não registra nenhuma resposta a estes apelos do poeta, não se completando o diálogo amoroso o que faz desvanecer a atmosfera criada por Akahito. Uma proposta sem resposta leva-nos a desconfiar se não seriam estes poemas frutos de sua imaginação e nunca correspondendo ao registro de uma experiência concreta, conforme era o hábito nos seus primórdios: - reunirem-se homens e mulheres num campo, por ocasião de trabalhos coletivos, e desafiarem-se mutuamente para o amor, criando uma obra poética fluida que 
seria transmitida da geração em geração até ser recolhida por algum poeta. O diálogo amoroso poético é relativamente comum dentro da antologia Manyooshuu, onde podemos a título de exemplos citar os de Nakatomi no Yakamori $^{5}$ e Sanono Otogamiotome (vol.15/3723 a 3778); os inúmeros Soomon de Ootomono Yakamochi ${ }^{6}$ e as mulheres de sua vida (vol. 3/403 a 408. vol. $8 / 581$ a $584.727-728.1624$ a 1630 . vol. $17 / 3931$ a 3942 , etc.); os diálogos amorosos de Ootomono Tabito ${ }^{7}$ trocados com uma mulher não identificada, quando regressava de Dazai para a capital (vol. 5/806 a 809); do mesmo Tabito com a yuujo Kojima (vol. 6/965 a 968), etc.

O tanka 361 do volume 3, também do poeta, é caracterizado como Soomon; mas já difere bastante destes "gracejos" ocasionais que Akahito dirige conforme vimos, às mulheres que vai encontrando pelo caminho. Utilizamos o termo "gracejo", do latim gratia, na acepção não corrente, de atividade de dirigir à pessoa almejada, uma consideração, proposta ou louvação sobre seus encantos. 0 tanka 361 diz o seguinte:

vol. $3 / 361$

“Akikazeno samuki assakeo Sanuno oka koyuramu kimi ni koromo kassamashio"

- A alguém (a você) que vai ao longo da colina de Sano na madrugada fria de vento outonal, emprestaria estas vestes.

O poeta utiliza o pronome pessoal da segunda pessoa "kimi" que segundo o dicionário da língua clássica "Jidaibetsú Kokugodaijiten - Joodaihen" da editora Sanseidoo, é: a via de regra, utilizado pela mulher sendo o seu referente o homem. b vez por outro, utilizado pelo homem sendo seu referente o homem. E segundo o dicionário "Nihon Kokugo Daijiten" da editora Shoogakukan: a na alta antiguidade (até 784 e marco inicial desconhecido), na maioria dos casos era utilizado pela mulher referindo-se ao homem; b há casos de utilização entre homens e casos de utilização entre mulheres; c na baixa antiguidade (de 794 a 1192), a sua utilização se toma mais livre, não havendo restrições quanto ao gênero.

Desta forma, quanto a utilização do pronome "kimi", apesar de ser mais plausivel considerar que cairia melhor aqui no poema como sendo da mulher dirigindo-se ao homem, não podemos nada afirmar.

Quanto ao ato de emprestar as vestes, dentro da poética Manyooshuu é utilizado nos poemas Soomon, caracterizando-se como símbolo do amor, aparecendo mulheres ofertando-as ao homem (ex: vol. 1/75. vol. 12/3011). Sendo o costume caracterizado como a dádiva da mulher para o homem, causa estranheza a inversão expressa por Akahito no poema.

Segundo Omadaka Hissataka em sua obra "Manyooshuu Chuushaku": "os professores Sassaki Nobutsuna e Kamono Mabuchi," consideram o poema como tendo sido elaborado pela esposa do poeta, mas anotado nos cadernos de Akahito; fora transcrito na dita obra como sendo dele mesmo. 0 mestre 
Motoori Norinaga do século XVIII, de sua parte, em sua obra "Manyooshuu Tamano Ogoto" considera o poema elaborado por uma yuujo (mulher da vida) que o dedica a Akahito, e em cujo poder este se encontrava"'(vol. 3 pág. 348-349). O próprio Omodaka Hissataka considera-o obra de Akahito, o poeta funcionando como Ghost writer.

Todos pois, são unânimes em considerar como autor real do poema, uma mulher. Levantaria de minha parte como caso a averiguar: 1 se este também não é fruto da imaginação do poeta e não de algum registro de fato ocorrido; 2 se for posta de lado a inversão, urge verificar se houve outros casos como este de o homem estar preocupado com a sua amada, que partiu numa madrugada fria de vento outonal, situação incomum na época. O sistema de poligamia da antiguidade consistia nas mulheres permanecerem em suas respectivas casas paternas e o homem visitá-las-ia ao anoitecer lá pernoitando e delas se despedindo ao amanhecer.

Outro poema em que o poeta utiliza o pronome "kimi" é o 947 , 'um hanka do 946, este já mencionado e considerado um desafio amoroso e imaginário. vol. 6/947

"Sumano amano shioyakiguinuno narenabaka hitohimo kimi o wassurete omowamu"

- Se os meus sentimentos aderissem a ti, como as vestes no corpo das jovens da salina, talvez por um dia pudesse esquecer-me de ti.

Sendo um hanka complementando o 946, este também seria um simples "gracejo" ocasional.

Se levantarmos a questão do pronome, seria a voz da yuujo (mulher da vida) dirigida ao poeta. Sendo porém um hanka, não poderíamos admitir autores diferentes para os dois poemas. Poderíamos questionar também se já não haveria mobilidade de emprego do pronome "kimi" como posteriormente consıatado, o que demandaria uma pesquisa exaustiva.

Nos dois casos, tanto o 361 como o 947, apesar destes apresentarem-se como parte do diálogo sentimental, o seu destinatário torna-se /vago devido à dúvida que paira quanto a autoria do poema. Não podemos duvidar dos conhecimentos gramaticais de um poeta da Corte e então vem-nos a idéia de que Akahito ou agia como Ghost writer ou imaginava situações amorosas, sem nunca tê-las vivido. Seria, pois, um dos pontos de partida de tentativas ficcionais nas obras poéticas japonesas.

Assim também, o poema 1426 do volume 8 do Manyooshuu é outro que deixa dúvida quanto à sua autoria pois, aparece o termo "seko", via de regra, utilizado pela mulher com referência ao esposo, o amante, o irmão ou ainda o seu amo e muito raramente utilizado pelo homem referindo-se a um amigo. Diz ele o seguinte:

vol. 8/1426 
"Waga seko ni missento omoishi umenohana soretomo miezu yukino furereba"

- Neva. e a flor de ameixeira que esperava mostrar-lhe não se revela (não se destaca).

Este poema vem inserido no referido volume dentro da divisão Zooka, subdivisão Primavera. O professor Ikeda Yassaburo, em sua obra "Takechino Kurohito e Yamabeno Akahito", considera como autor do poema uma mulher, aludindo à utilizaçăo do termo "seko", já destacado. Fica a dúvida sobre o autor e o destinatário e novamente a pergunta: terá Akahito imaginado a circunstância ou terá ele escrito a pedido de alguém? $O$ movimento na natureza, captado em seus tanka paisagísticos é outra tônica de Akahito. E neste há a queda constante da neve que dilue os contomos da flor, elemento este que reforça a hipotese de ser o poema de sua autoria.

Os tanka 360 e 942 são os únicos em que o poeta menciona o termo "imo", que na época significava "esposa". $0360 \mathrm{diz}$ o seguinte:

vol. $3 / 360$

"Shiohinaba tamamo karitsume ieno imo ga hamazuto kowaba nanio shimessamu"

- Quando a maré baixar reserve as ricas algas, se não o que ofertar à eposa que $o$ anseia?

Pelo verbo "karitsume" (colher e reservar), utilizado no referido tanka, no modo imperativo, podemos interpretá-lo de duas maneiras: a - o poeta está sugerindo a terceiros a coleta das algas e neste caso a esposa mencionada não está relacionada a si próprio; b o imperativo é para si mesmo e o poema toma novamente o caráter de monólogo. E neste caso ele intenta criar uma atmosfera de fantasia consigo mesmo, e a figura da esposa está remota num plano distante. E esta é a minha opinião acompanhando o poeta através dos seus Soomon. Apesar de declarar o seu destinatário claramente, Akahito se fecha sobre si e vive a sua solidão.

Os poemas $940-941$, dizem respeito à sua saudade do lar, provocada pelo distanciamento geográfico que as viagens o obrigam. Fogem de certa forma da correspondência humana do Soomon. O chooka 938 que precede estes hanka 940-941 é uma autêntica exaltação da terra com a louvação às enseadas de Fujii, local visitado repetidas vezes pela comitiva imperial. Valoriza ele estas viagens, com as belezas das praias, das areias brancas, a boa pescaria e a fabricação de sal ativada na localidade. $O$ hanka 940 no entanto se revela como um verdadeiro queixar-se do poeta, pelas noites mal dormidas, deixando amarrotanto as relvas das colinas de Inami, em desalinho com os pensamentos voltados para a sua casa. 0 poema 941 , transmite já a alegria do autor no seu caminho de retorno à capital, esta sensação aflorando naturalmente nesta sua obra. Tanto. o 940 como o 941 fogem um tanto da temática do chooka 938 a 
que deveriam completementar. Houve pois, nestes seus hanka um sutil deslize, onde um queixume honesto do ser humano não se conteve. São novamente os seus monólogos íntimosique vêm à tona. Nota-se atrás disto tudo que a situação política e social de Nara já lhe permitia estes desvios do Zooka, onde a pura exaltação à terra do imperador vem mesclada de queixumes particulares do poeta. Isto, como conseqüéncia, vai acarretar o desmembramento do hanka de seu chooka, quebrando-lhes a estrutura formal através da quebra da estrutura temática correspondente, em sua base.

Akahito, talvez inconsciente, acostumado no seu monologar solitário ou talvez por uma curiosa "inabilidade" na execução do seu Zooka, sem mesmo ter a noção de seu ego, vai transgredindo uma forma poética milenar e tradicional.

Repassando-se o olhar pelos Soomon do poeta aqui destacados, verificamos que os números 362-363 são "gracejos" ocasionais sem registros de respostas e que tendem para situaçð̃es imaginárias; os números 361, 976 e 1426 criam situaçðes mal definidas com a utilização dos termos "kimi" e "seko" 0 poeta aqui agindo como Ghost writer talvez estabeleça um dos pontos de partida dos poemas de pura imaginação que se desenvolveriam mais tarde para os poemas ficcionais. O número 360 evidencia o costume de monologar do poeta que não chega a ser uma introspeç̧ão e conscientização do seu ego e o resultado deste monologar solitário e poético conduz o despreendimento do chooka-hanka, visto em 938-940-941. O poeta desta forma, inconsciente de seu papel, leva o poema japonês, tradicionalmente de criação espontânea, para a criação fictícia, abrindo novos caminhos em sua poética. Concomitante isto, com o seu monologar vai rompendo uma forma de poetar, chooka-hanka que mais tarde, na litëratura clássica da baixa antiguidade japonesa, cai no desuso quase que total.

Resta-nos uma passada de olhos nos Zooka do poeta onde tentaremos apontar estas suas posturas talvez, repetimos, inconscientes.

O chooka 324 e o seu hanka 325, segundo suas anotaçōes, foram elaborados quando da escalada ao monte sagrado de Mimoro e se caracterizam como Zooka de exaltação à antiga capital de Assuka. Diz o 324 o seguinte: vol. $3 / 324$

"Mimoro" kamunabi yamani ioessashi shijini oitaru tsuga no kino iya tsugui tsuguini tamakazura tayurukotonaku aritsutsumo yamazu kay awamu. Assukano furuki miyakowa yamatakami kawatooshiroshi haruno hiwa yamashi migahoshi akino yowa kawashi sayakeshi tazuwa midare yuukirini kawazuwa sawaku mirugotoni nenomishi nakayu inishie omoeba"

- Como indica o "tsuga", que prolifera expandindo seus mil ramos no monte sagrado de Mimoro, tais os cipós, que um após outro não cessam de crescer, não só hoje, mas por dias infindáveis; retornarão (as pessoas) a esta antiga capital de Assuka, onde as montanhas se elevam soberbas, sendo belas em dias primaveris e em noites de 
outono, ouvem-se murmúrios límpidos do rio; nas nuvens matinais, cegonhas em desalinho esvoaçam e nas névoas do entardecer coaxam as rås . Lágrimas irrompem-me quando isto presencio com o pensamento no passado.

A apologia à antiga capital de Assuka se faz através de um encadeamento de imagens que se sobrepð̃em pelo processo de paralelismo antagônico de montanhas-rios, primavera-outono, noite-dia, nuvem matinal-névoa do entardecer. Pelo aproveitamento de palavras parcialmente homófonas, tsuga (nome de vegetação) e tsugue (significando seqüência) que possibilita o desenvolvimento semântico do poema. E pelas equivalências semânticas que dão 0 significado unitário do grupo (o apego: dos cipós aos ramos de tsuga e as visitas que se repetem à velha capital).

Nota-se pelo conteúdo do chooka que o poeta está a serviço da Corte. Em contraposição, o hanka 325, apesar de expressar a idéia central do chooka comporta uma estrutura que, se desvinculada daquele, sobreviveria por si só, sem outras implicações. Diz ele o seguinte:

vol. $3 / 325$

“Assukagawa kawayodo sarazu tatsukirino omoi sugubeki koini aranakuni"

- Devoçбes

Serão neblinas que pairam em calmarias do rio Assuka

Apesar de sintetizar a temática do chooka 324 , as devoções aqui mencionadas pelo processo de analogia, poderiam ser consideradas como Soomon do sentimento amoroso, generalizado, em nivel de idéias, bem do gosto do poeta, onde não há especificaçōes do seu destinatário. A desvinculação chooka-hanka aqui também será possível.

Finalizando citaremos aqui o chooka 923 e seus hanka $924-925$ que se caracterizam como típicos Zooka de solenidades. Segundo as anotaçōes antepostas ao poema 920 de Kassano Kanamura, talvez o mais importante dos poetas da Corte da época, considerando-se a posição que sempre seus poemas ocupam na seqüência das obras encomendadas por esta, esclarece ela nos seguintes termos: "Verão-maio do ano 2 da era Shinki (725)-viagem imperial à Yoshino"

vol. $6 / 923$

"Yassumishishi wagaookimino takashirassu Yoshinono miyawa tatanazuku aogakigomori kawanamino kiyoki kawachizo harubewa hanassakioori akissareba kiritachiwatari sonoyamani iyashikushikuni konokawano tayurukotonaku momoshikino, oomiyabitowa tsunenikayowamu"

- O palácio de Yoshino, erguido pomposamente por este nosso magnífico imperador e que governa todos os cantos, é cercado pelas 
montanhas que se avolumam esverdeantes e onde os rios são límpidos. Na primavera flores copiosas fazem inclinar suas hastes e no outono névoas tudo encobrem. Como estas montanhas soberbas e como estes rios eternos, os membros da Corte aqui sempre retornarão.

vol. 6/924

"Miyoshinono kissayamano mano konureniwa kokodamo sawaku torino koekamo"

- So, na copa de uma árvore, ouve-se o tagarelar dos pássaros

Em vales do monte Kissa, dos retiros de Yoshino.

vol. 6/925

"Nubatamano yono fukeyukeba hissaki ouru kiyoki kawarani Chidori shibanaku"

- Quando a noite se faz alta, nas margens límpidas do rio onde é denso o verde, gralhas cantam de tempo em tempo.

O paralelismo por oposição e contiguidade se repetem no chooka 923 , onde o modelo tradicional de exaltação ao império se processa solenemente com a colocaçáo do termo "o nosso magnífico imperador" na sua abertura.

As palavras porém, já gastas por técnicas maneiristas, talvez nem mais empolgassem o próprio poeta que, aproveitando-se da mesma paisagem, cria dois hanka transcendendo os módulos do chooka e propondo-as, talvez, seu malgrado, como obras de arte acabadas em si.

Mesmo acompanhando a comitiva imperial, o poeta se isola do grupo e através da observação atenta da natureza, atividade herdada do guarda florestal seu predecessor, consegue expressar tanto em 924 como no 925, por exemplo, com o cantar do pássaro, o triste silêncio envolvente da natureza. $E$ nesta solidão imensa que impregna o seu íntimo e o seu ambiente, o poeta que não resiste em criar imagens fictícias no seu monólogo, faz desmoronar dentro do Zooka, o formal chooka-hanka, que vai aos poucos sendo abandonado como poesias do passado. 
Notas

1 - O trecho por nós consultado encontra-se em "Nihonshoki" de autoria do prof. Takeda Yuukichi, cap. 15, pág. 506, in Nihon Koten Zensho, edit. Assahi Shimbunsha, 1966.

2 - Idem nota (1), cap. 29, pág. 224.

3 - Poeta da Corte da imperatriz Jitoo (686-697) e do imperador Monmu (697707).

4 - "Yamabe no Akahito" in Manyooshuu Kooza, vol. 6, pág. 124-126.

5 - Banido por motivo de ligações ilícitas que manteve com Sonono Otogamiotome. O casal deixa 63 Soomon, em forma de diálogos amorosos. Viveu de 718 (?) a 785.

6 - Falecido em 782, é considerado como um dos elaboradores da antologia poética Manyooshuu.

7 - Pai de Ootomo no Yakamochi, da nota (6). De família tradicional da aristocracia, é enviado como chefe da província de Dazai, no sul do país, posto de contacto com o continente asiático. Viveu de 665 a 731.

8 - Autor da obra "Manyooshuu no Kenkyuu". (1872-1963).

9 - Autor da obra "Manyoo Koo". (1697-1769).

\section{BIBLIOGRAFIA}

IKEDA, Yassaburo. "Takechi no Kurohito. Yamabe no Akahito": in Nihon Shijinsen (3), edit. Chikuma Shoboo, Tokyo, 1970.

NAKANISHI, Sussumu. "Manyoo no Sekai", edit، Chuookooronsha, Tokyo, 1973.

KITAY AMA, Shigueo. "Manyoo no Jidai", edit. Iwanami, Tokyo, 1974.

OMODAKA, Hissataka. "Manyooshuu Chuushaku", vol. 3/6/8, edit. Chuookooronsha, Tokyo, 1967. 